\title{
Geleneksel Donatılmış Betonarme Bağ Kirişlerin Şekil Değiştirme Esaslı Hasar Sınırlarının Araştırılması
}

\author{
Rohullah Jamal $^{1 *}$, S. Bahadır Yüksel ${ }^{2}$ \\ Geliş / Received: $30 / 04 / 2020$ \\ Revize / Revised: 22/09/2020 \\ Kabul / Accepted: 01/10/2020

\section{$\overline{\mathbf{O Z Z}}$}

Türkiye Bina Deprem Yönetmeliği 2018 (TBDY, 2018)'de geleneksel donatılmış betonarme bağ kirişleri için öngörülen şekil değiştirme esaslı hasar sınırları analitik olarak incelenmiştir. Geleneksel donatılmış betonarme bağ kirişlerinin çekme ve basınç donatısı oranı, enine donatı çapı ve aralığı sabit tutulmuş net açıklık / derinlik oranı ve beton basınç dayanımını değiş̧irilerek SAP 2000 programı ile moment-eğrilik değerleri hesaplanmıştır. $\mathrm{Bu}$ çalışmada; gerçek malzeme davranışları esas alınmıştır. Elde edilen momenti-eğrilik ilişkilerinden betonarme bağ kirişlerinin elastik ötesi davranışları incelenmiştir. Geleneksel donatılmış betonarme bağ kirişi modelleri için moment-eğrilik ilişkilerinden elde edilen veriler kullanılarak TBDY, (2018)'de verilen hasar sınır değerleri betonarme bağ kiriş modelleri için hesaplanmıştır. Şekil değiştirme değerleri TBDY (2018)'de tanımlanmış olan göçmenin önlenmesi (GÖ), kontrollü hasar $(\mathrm{KH})$ ve sınırlı hasar $(\mathrm{SH})$ performans seviyeleri için hesaplanmıştır. Geleneksel donatılmış betonarme bağ kirişleri için üç ayrı hasar sınırı ve bu hasar sınırlarına karşı gelen birim şekil değiştirme değerleri incelenmiştir. Geleneksel donatılmış betonarme bağ kirişlerde farklı performans düzeyi için beton ve donatı çeliği birim şekil değiştirmeleri ve plastik dönmeleri hesaplanarak performans düzeyleri araştırılmıştır. GÖ ve KH performans düzeyleri için plastik dönmelerin hasar sınırları; akma eğriliği, kopma eğriliği, plastik mafsal uzunluğu, kesme açıklığı ve boyuna donatı çapının fonksiyonu olarak tanımlanmıştır. Bu çalışmada; geleneksel donatılmış bağ kirişlerinin beton basınç dayanımının akma momentine $\left(M_{y}\right)$, GÖ ve KH performans düzeyleri için plastik dönme sınırlarına $\left(\theta_{P}^{(K H)}\right.$ ve $\left.\theta_{P}^{(G O ̈)}\right)$ etkili olduğu gözlemlenmiştir. Net açıklık derinlik oranın $\left(l_{n} / h\right)$ artırılması; geleneksel donatılmış betonarme bağ kirişlerininGÖ ve KH performans düzeyleri için izin verilen plastik dönme sınırlarına $\left(\theta_{P}^{(K H)}\right.$ ve $\left.\theta_{P}^{(G O ̈)}\right)$ ve akma durumu için yer değiştirmiş eksen dönmesi üzerine $\left(\theta_{y}\right)$ etkili olduğunu ispatlanmıştır.

Anahtar Kelimeler-Moment-Ĕ̆rilik, Performans Düzeyleri, Hasar Sınırları, Birim Şekil Değ̈iștirme Sınırları, Plastik Dönme

1*Sorumlu yazar iletişim: jamal.rohullah@gmail.com (https://orcid.org/0000-0001-5987-8502)

Konya Teknik Üniversitesi, Mühendislik ve Doğa Bilimleri Fakültesi, İş̧aat Mühendisliği Bölümü, Konya, Türkiye

2İletişim: sbyuksel@ktun.edu.tr(https://orcid.org/0000-0002-4175-1156)

Konya Teknik Üniversitesi, Mühendislik ve Doğa Bilimleri Fakültesi, İnşaat Mühendisliği Bölümü, Konya, Türkiye 


\title{
Investigation of Damage Limits of Conventional Reinforced Concrete Coupling Beams
}

\begin{abstract}
Deformation based damage limits of conventional reinforced concrete coupling beams were analytically investigated considering the Turkish Seismic Building Code 2018 (TSC, 2018). Moment-curvature values of the conventional reinforced concrete beams were calculated with the SAP 2000 programs by taking constant tension and compression reinforcement ratios, transverse reinforcement diameter and spacing's and changing the net span/depth ratio and concrete compressive strengths. In this study, real material behaviour was taken into account. Inelastic behaviors of reinforced concrete coupling beams are investigated from the moment-curvature relations. The damage limit values given in TSC (2018) were calculated for reinforced concrete coupling beam models using the data obtained from moment-curvature relationships of conventionally reinforced concrete coupling beams models. Strain values are calculated for the collapse prevention (CP), controlled damage (CD) and limited damage (LD) performance levels defined in TSC (2018). Three different damage limits and unit strain values corresponding to these damage limits were examined for conventionally reinforced concrete coupling beams. The performance levels of the concrete and reinforcement steel deformations and plastic rotations were calculated for different performance levels of conventional reinforced concrete coupling beams. Damage limits of plastic rotations of the CP and CD performance levels are defined as functions of yield curvature, maximum curvature, plastic hinge length, shear length, and longitudinal reinforcement diameter. In this study; it has been observed that the concrete compressive strength affect the yield moment $\left(M_{y}\right)$, plastic rotation limits $\left(\theta_{P}^{(C D)}\right.$ and $\left.\theta_{P}^{(C P)}\right)$ for performance levels of $\mathrm{CP}$ and $\mathrm{CD}$ of conventional reinforced coupling beams. It is proven that the net span depth to ratio $\left(l_{n} / h\right)$ effect the; plastic rotation limits $\left(\theta_{P}^{(C D)}\right.$ and $\left.\theta_{P}^{(C P)}\right)$ of the $\mathrm{CP}$ and $\mathrm{CD}$ performance levels and yield chord rotation $\left(\theta_{y}\right)$ for the conventional reinforced concrete coupling beams.
\end{abstract}

Keywords-Moment-Curvature, Performance Levels, Damage Limits, Strain Limits, Plastic Rotation 


\section{GíRiș}

Yapı taşıyıcı sisteminin doğrusal sınır ötesindeki kapasitesinin de dikkate alındığı hesap yöntemleri son yıllarda yaygınlaşmıştır. Yapının dayanım ve yer değiştirme kapasitelerini ortaya çıkaran, göçme aşamasına kadar oluşacak hasarların adım adım izlenebildiği doğrusal olmayan hesap yöntemleri kullanılarak, yapı davranışı daha iyi anlaşılabilmektedir. Performans esaslı değerlendirme yönteminin en önemli aşamalarından birisi yapısal elemanların her birinin hasar düzeylerinin belirlenmesidir. Yapı performansı, amaçlanan deprem istemi etkisinde yapıda oluşması beklenen hasar durumu ile ilişkilidir. Doğrusal olmayan değerlendirme yöntemi ile analiz edilen yapılardaki yapısal elemanların kesitlerinde oluşan şekil değiştirme değerlerinin, yürürlükte olan yönetmelikteki kesit hasar seviyesine tekabül eden şekil değiştirme üst sınır değerleri ile kıyaslanması ile kesitin hasar seviyesi elde edilir. Dolayısı ile yapıların deprem güvenliğini belirlemede kesit hasar sınır değerlerinin doğru bir şekilde elde edilmesi oldukça önem arz etmektedir. [1, 2].

Bağ kirişleri genellikle orta ve yüksek binalarda, merdivenlerin ve asansörlerin çevresinde bulunan perde duvarların bağlanması amacıyla kullanılmaktadır. Bă̆ kirişlerinin deformasyon yapabilmesi elemanın kesme deformasyonu yapabilme kapasitesine bağlıdır. Bağ kirişleri iki perde duvarı birleştirerek kesme etkisinin perde duvarlara aktarılmasını sağlayarak, perde duvarların eğilme rijitliğinin artmasına sebep olmaktadır. Buna ilaveten bağ kirişleri, aşırı plastik deformasyonlara maruz kalarak sismik enerjisinin yutulmasını sağlarlar. Bağ kirişlerinin tasarımında amaç, bağ kirişlerinin sünek davranmasını, sismik yükler etkisi altında fazla dönme yapabilmesini ve daha fazla enerji tüketilmesini sağlayabilmektir [3]. Bă̆ kirişli betonarme perde duvarlar, orta ve yüksek katlı binalarda kullanılmaktadır. Bu tip taşıyıcı sistemler günümüzdeki yaygın olarak kullanılan sistemlerden biridir [4]. Boşluklu perde duvarlı taşıyıcı sistemlerde, sismik kuvvetler, perde duvarları ve bağ kirişleri tarafından bir çerçeve sistemi gibi karşılanmaktadır. Bu nedenle bağ kirişleri ve perde duvarları uygun bir şekilde tasarlanması gerekmektedir [5].

Türkiye Bina Deprem Yönetmeliği (TBDY, 2018)'de sünek elemanlar için kesit düzeyinde üç hasar durumu ve hasar sınırı tanımlanmıştır. Bunlar Sınırlı Hasar (SH), Kontrollü Hasar (KH) ve Göçme Öncesi Hasar (GÖ) durumları ve bunların sınır değerleridir. Sınırlı hasar ilgili kesitte sınırlı miktarda elastik ötesi davranışı, kontrollü hasar kesit dayanımının güvenli olarak sağlanabileceği elastik ötesi davranışı, göçme öncesi hasar durumu ise kesitte ileri düzeyde elastik ötesi davranışı tanımlamaktadır. Gevrek olarak hasar gören elemanlarda bu sınıflandırma geçerli değildir [6].

$\mathrm{Bu}$ çalışmada; C30 ve C45 beton sınıfı, farklı çekme ve basınç donatısı oranlarına ve farklı net açıklık/derinlik oranına sahip geleneksel donatılmış betonarme bağ kirişlerinin moment-eğrilik ilişkisi değerleri SAP 2000 [7] programı ile hesaplanmıştır. TBDY 2018'e göre KH performans düzeyi GÖ performans seviyesinin \%75'i olarak tanımlanmıştır. SH performans düzeyinde ise beton ve donatı çeliği için izin verilen birim kısalma ve uzaması sabit olarak verilmiştir. SH performans düzeyi için taşıyıcı sistemde plastik mafsal oluşumuna izin verilmemiştir $\left(\theta_{p}^{(S H)}=0\right)$. Elde edilen moment ve eğrilik değerlerinden yararlanarak TBDY (2018)'e göre kesit hasar sınırları hesaplanmıştır. Bunun için 6 tip toplam 30 adet geleneksel donatılmış betonarme bağ kirişi tasarlanmıştır. Tip-1, 2 ve 3 olan betonarme bağ kirişlerde C30, Tip 4, 5 ve 6 olan betonarme bağ kirişlerde C45 beton sınıfları ve B420C donatı sınıfı kullanılmıştır. Tip-1, 2, 3, 4, 5 ve 6 olan geleneksel donatılmış betonarme bağ kirişlerde değişen parametreler; beton sınıfi, çekme ve basınç donatı oranı ve net açıklık/derinlik oranıdır. Tüm elemanlarda $10 \mathrm{~mm}$ çapında $50 \mathrm{~mm}$ aralığında $(\Phi 10 / 50 \mathrm{~mm})$ etriyeler ele alınarak hasar sınırları TBDY 2018'e göre hesaplanmıştır. Çalışmada değişen parametrelerin hasar sınırlarına etkisi araştırılmıştır. TBDY 2018'e göre, GÖ performans hasar sınırları izin verilen beton birim kısalmaları $\left(\varepsilon_{c}^{(G O ̈)}\right)$, donatı çeliği için izin verilen birim uzamaları $\left(\varepsilon_{S}^{(G O ̈)}\right)$ ve izin verilen performans dönme açıları $\left(\theta_{P}^{(G O ̈)}\right)$ hesaplanmıştır [6].

\section{TBDY 2018'E GÖRE İZIN VERILEEN ŞEKIL DEĞIŞTİRME HASAR SINIRLARI}

Göçme önlenmesi, kontrolü hasar ve sınırlı hasar performans düzeyi için yapılacak performans değerlendirmesinde kullanılmak üzere, yüksek binalar ve yeni betonarme bina elemanlarında yayılı plastik davranış modeline göre hesaplanan beton ve donatı çeliği toplam birim şekil değiştirmeleri için izin verilen hasar sınırları aşağıda tanımlanmıştır. GÖ, KH ve $\mathrm{SH}$ performans düzeyi için beton birim kısalması 
$\left(\varepsilon_{c}^{(G O ̈)}, \varepsilon_{c}^{(K H)}\right.$ ve $\left.\varepsilon_{c}^{(S H)}\right)$, donatı çeliği birim uzaması $\left(\varepsilon_{s}^{(G O ̈)}, \varepsilon_{s}^{(K H)}\right.$ ve $\left.\varepsilon_{s}^{(S H)}\right)$ ve izin verilen plastik dönme sınırları $\left(\theta_{P}^{(G O ̈)}, \theta_{P}^{(K H)}\right.$ ve $\left.\theta_{P}^{(S H)}\right)$ dikdörtgen en-kesitli kolon, kiriş ve perdeler için Tablo (1)'de verilen denklemler ile hesaplanmaktadır.

Tablo 1. Betonarme elemanları için izin verilen şekil değiştirme üst sınırların denklemleri [6]

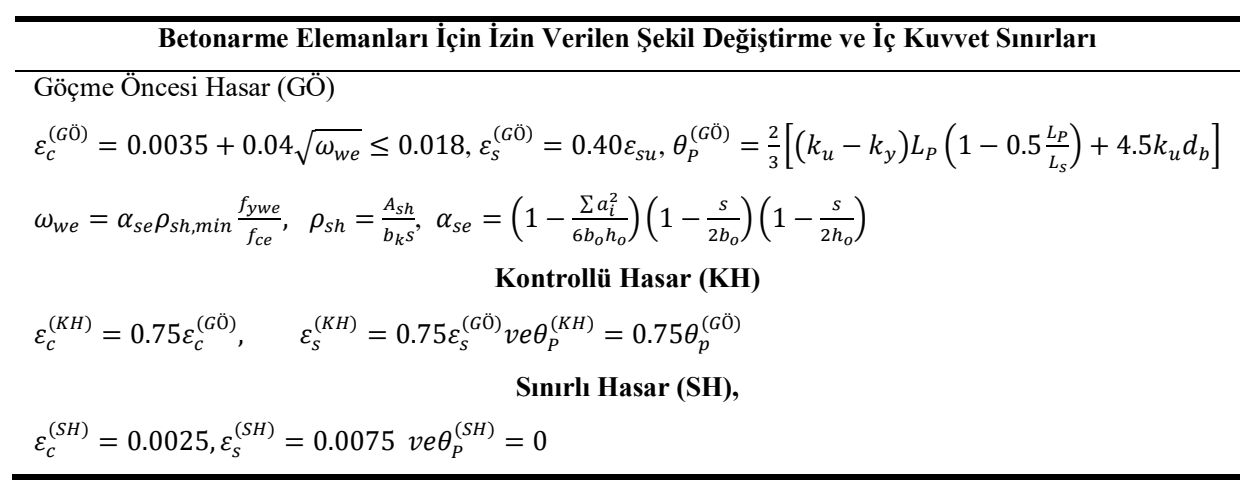

Tablo 1'de verilen $\varepsilon_{c}^{(G O ̈)}, \varepsilon_{c}^{(K H)}$ ve $\varepsilon_{c}^{(S H)}$ sirasiyla GÖ, KH ve SH performans düzeyi için izin verilen beton birim şekildeğiştirmesidir. $\varepsilon_{s}^{(G O ̈)}, \varepsilon_{s}^{(K H)}$ ve $\varepsilon_{s}^{(S H)}$ sırasıyla GÖ, KH ve SH performans düzeyi için izin verilen donatı birim şekildeğiştirmesini göstermektedir. $\theta_{P}^{(G O ̈)}, \theta_{P}^{(K H)}$ ve $\theta_{P}^{(S H)}$ sırasıyla göçmenin önlenmesi, kontrolü hasar ve sınırlı hasar performans düzeyi için izin verilen dönme açılarıdır. Tablo (1)'de verilen denklemlerde $\omega_{w e}$ etkin sargı donatısının mekanik donatı oranını, $\varepsilon_{s u}$ donatının çekme dayanımına karşı gelen birim uzamasını, $k_{u}$ maksimum eğriliğini, $k_{y}$ akma eğriliğini, $L_{P}$ plastik mafsal uzunluğunu, $L_{s}$ kesme açıklığını ve $d_{b}$ boyuna donatı çapını göstermektedir. Hesaplarda yönetmeliğe göre boyuna donatı çapı çekme donatısının ortalama çapı olarak tanımlanmaktadır.

GÖ performans düzeyi için izin verilen beton birim kısalması $\left(\varepsilon_{c}^{(G O ̈)}\right)$ denklemindeki ilk terim $(0.0035)$ sargısız betonun birim kısalmasına karşı gelmektedir. Etkin sargı donatısının mekanik donatı oranı $\left(\omega_{\text {we }}\right)$, sarg1 donatısı etkinlik katsayısı $\left(\alpha_{\text {se }}\right)$ ve kesitte hacimsel enine donatı oranı $\left(\rho_{s h}\right)$ Tablo (1)'de verilen denklemler ile hesaplanmıştır. Tablo (1)'de, $\alpha_{\text {se }}, \rho_{s h, m i n}, f_{y w e}, A_{s h}$ ve $\rho_{s h}$ sırasıyla sarg1 donatısının etkinlik katsayısını, dikdörtgen kesitte iki yatay doğrultuda hacimsel enine donatı oranının küçük olanını, enine donatının ortalama (beklenen) akma dayanımını, göz önüne alınan doğrultuda enine donatının alanını ve hacimsel oranını göstermektedir. Denklemlerde $b_{k}$ dik doğrultudaki çekirdek boyutunu (en diştaki enine donatı eksenleri arasındaki uzaklık), $s$ enine donatı aralığını, $b_{o}$ ve $h_{o}$ sargı donatısı eksenlerinden ölçülen sargılı beton boyutlarını, $a_{i}$ bir etriye kolu veya çiroz tarafından mesnetlenen boyuna donatıların eksenleri arasındaki mesafesini göstermektedir. Sınırlı hasar performans düzeyi için taşıyıcı sistemde plastik mafsal oluşumuna izin verilmeyecektir $\left(\theta_{P}^{(S H)}=0\right)$.

Akma durumu için yer değiştirmiş plastik mafsal eksen dönmesi $\theta_{y}$ Denklem (1) ile hesaplanmaktadır. Denklem (1)'de $f_{c e}$ ve $f_{y e}$ betonun ortalama (beklenen) basınç dayanımı ile donatının ortalama akma dayanımıdır. $\eta$ katsayısı kiriş ve kolonlarda $\eta=1$, perdelerde ise $\eta=0.5$ 'dir. TBDY (2018)'de betonun ortalama (beklenen) basınç dayanımı ve donatının ortalama akma dayanımı $f_{c e}=1.3 f_{c k}$ ve $f_{y e}=1.2 f_{y k}$ olarak verilmiştir. $f_{c k}$ ve $f_{y k}$ sırasıyla beton karakteristik basınç dayanımı ve donatı çeliği karakteristik akma dayanımidir.

$$
\theta_{y}=\frac{k_{y} L_{s}}{3}+0.0015 \eta\left(1+1.5 \frac{h}{L_{S}}\right)+\frac{k_{y} d_{b} f_{y e}}{8 \sqrt{f_{c e}}}
$$

Bu çalışmada geleneksel donatılmış betonarme bağ kirişlerinin deprem performansının belirlenmesi için TBDY, (2018)'de verilen kurallara göre sabit geometriye ve farklı parametrelere sahip 6 tip toplam 30 adet bağ 
kiriş modeli tasarlanmıştır (Çizelge 3 ve 4). Tasarlanan geleneksel donatılmış betonarme bağ kirişlerde gerçek malzeme davranışları esas alınmıştır. Geleneksel donatılmış betonarme bağ kirişlerde farklı beton basınç dayanımı, çekme ve basınç donatısı oranı ve net açıklık/derinlik oranına göre moment-eğrilik ilişkilerinden; akma eğriliği $\left(k_{y}\right)$, akma momenti $\left(M_{y}\right)$, göçme öncesi eğriliği $\left(k_{u}\right)$, göçme öncesi eğilme momenti $\left(M_{u}\right)$ ve eğrilik sünekliği $(\mu)$ değerleri elde edilmiştir. Betonarme kiriş modellerinin moment-eğrilik ilişkilerinden elde edilen sonuçlara göre kiriş kesitlerinin davranışları incelenmiştir. Geleneksel donatılmış betonarme bağ kiriş modellerinde yapılan performans değerlendirmesinde GÖ, KH ve SH performans seviyeleri için şekil değiştirme ve iç kuvvet sınır değerleri hesaplanmıştır. Geleneksel donatılmış betonarme bağ kiriş elemanlarında sargı donatısı oranı sabit tutularak, farklı parametre olarak net açıklık/derinlik oranı, çekme ve basınç donatısı oranı ve beton basınç dayanımı ele alınmıştır. Geleneksel donatılmış betonarme bağ kirişlerinin beton ve donatı çeliği birim şekil değiştirmeleri, plastik mafsal akma dönmesi ve plastik dönmeleri hesaplanarak bağ kiriş kesitlerinin performans düzeyleri araştırılmıştır. Çalışmada çekme ve basınç donatısı miktarı (4Ф20, 4Ф26 ve 4Ф32) değişilerek enine donatı çapı ve aralığ $\Phi 10 / 50 \mathrm{~mm}$ olarak sabit alınmıştır. Net açıklık-derinlik oranı $\left(l_{n} / h=\right.$ 2, 2.5, 3, 3.5 ve 4) ve beton sınıfı C30 ve C45 değiştirilerek parametrik çalışma yapılmıştır.

Geleneksel donatılmış betonarme bağ kirişlerde süneklik oranı, kesitin dayanımında önemli bir azalma olmadan yapabileceği doğrusal ötesi deformasyon kapasitesi olarak tanımlanır. Eğilme etkisi altındaki elemanların sünekliği, eğrilik süneklik katsayısı $(\mu)$ Denklem (2) ile hesaplanmaktadır. Eğrilik süneklik katsayısı, kesitin kırılma anında yaptığı eğriliğin $\left(k_{u}\right)$, çekme donatısının aktığı anda kesitte oluşan eğriliğe $\left(k_{y}\right)$ oranıdir [8].

$$
\mu=\frac{k_{u}}{k_{y}}
$$

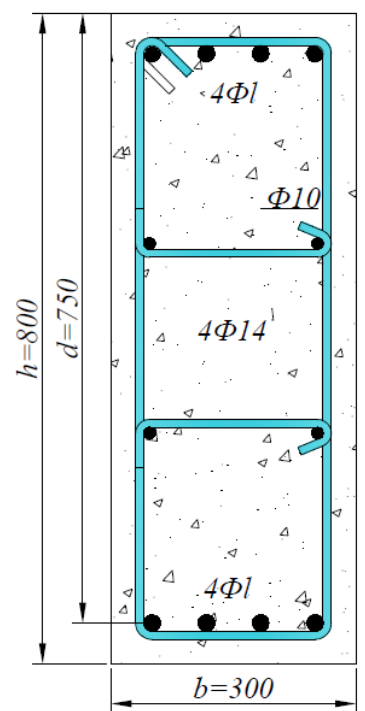

Şekil 1. Geleneksel donatılmış betonarme bağ kirişlerinin en-kesit boyutları ve donatı düzeni

\section{MATERYAL VE METOT}

Geleneksel donatılmış betonarme bağ kirişi modellerinde moment-eğrilik analizlerinden $M_{y}, k_{\mathrm{y}} M_{u}, k_{\mathrm{u}}$ ve $\mu$ değerleri hesaplanmıştır. Moment ve eğrilik değerleri SAP 2000 fiber analiz modellerinden elde edilmiştir. Geleneksel donatılmış betonarme bağ kirişlerinin hasar sınırları TBDY 2018'e göre hesaplanmıştır. Şekil değiştirme ve iç kuvvet sınırlarının hesaplanmasında TBDY, (2018)'de tanımlanmış üç farklı hasar sınırı olan GÖ, KH ve SH performans seviyeleri göz önünde bulundurulmuştur. Geleneksel donatılmış betonarme bağ kirişlerinde farklı performans seviyesi için oluşan şekil değiştirme ve iç kuvvet sınırları hesaplanarak Çizelgeler 
ve Grafikler halinde sunulmuştur. Birim şekil değiştirme istemlerinin belirlenmesi plastik şekil değiştirmelerin meydana geldiği betonarme sünek taşıyıcı sistem elemanlarında, farklı kesit hasar sınırlarında GÖ, $\mathrm{KH}$ ve $\mathrm{SH}$ performans düzeyleri için izin verilen beton ve donatı çeliği şekil değiştirme üst sınırları hesaplanmıştır. Yı ̆ğılı plastik davranışına göre modellenen geleneksel donatılmış betonarme bağ kirişlerinin moment-eğrilik iliş̧ilerinden elde edilen $k_{\mathrm{y}}$ ve $k_{\mathrm{u}}$ değerlerine göre plastik mafsal dönmeleri hesaplanmıştır. Geleneksel donatılmış betonarme bağ kirişlerde çekme ve basınç donatısı miktarı 4Ф20mm, 4Ф26mm ve 4Ф32mm, enine donatı çapı $\Phi 10 \mathrm{~mm}$ ve aralığ $50 \mathrm{~mm}(\Phi 10 / 50 \mathrm{~mm})$ olarak belirlenerek beton sınıfı C30 ve C45 olarak seçilmiştir. Tüm elemanlarda boyuna ve enine donatı çeliği olarak B420C donatı sınıfı seçilmiştir. Geleneksel donatılmış betonarme bağ kirişlerinin tasarımında kullanılan malzeme özellikleri Tablo (2)'de, verilmiştir. Bağ kirişlerinin çekme ve basınç donatısı oranları ve modellerinde kullanılan parametreler sırasıyla Tablo (3) ve (4)'te verilmiştir.

Tablo 2. Malzeme modellerinde kullanılan parametreler (TBDY, 2018)

\begin{tabular}{lll}
\hline Malzeme & Parametre & Değer \\
\hline \multirow{3}{*}{ Beton Sınıfı: C30,45 } & Sargısız betonun maksimum gerilmeye ulaştığı birim şekil değiştirme değeri $\left(\varepsilon_{\mathrm{co}}\right)$ & 0.002 \\
& Sargısız betonun nihai birim şekil değiştirmesi $\left(\varepsilon_{\mathrm{cu}}\right)$ & 0.0035 \\
& Karakteristik beton basınç dayanımı $\left(\mathrm{f}_{\mathrm{ck}}\right)$ & $30,45 \mathrm{MPa}$ \\
\hline \multirow{3}{*}{ Donatı Çeliği: B420C } & Donatı çeliğinin akma birim şekil değiştirmesi $\left(\varepsilon_{\mathrm{sy}}\right)$ & 0.0021 \\
& Donatı çeliğinin pekleşme birim şekil değiştirmesi $\left(\varepsilon_{\mathrm{sp}}\right)$ & 0.008 \\
& Donatı çeliğinin kopma birim şekil değiştirmesi $\left(\varepsilon_{\mathrm{su}}\right)$ & 0.08 \\
& Donatı çeliğinin karakteristik akma dayanımı $\left(\mathrm{f}_{\mathrm{yk}}\right)$ & $420 \mathrm{MPa}$ \\
& Donatı çeliğinin karakteristik kopma dayanımı $\left(\mathrm{f}_{\mathrm{su}}\right)$ & $550 \mathrm{MPa}$ \\
\hline
\end{tabular}

Tablo 3.Tip-1, 2 ve 3 olarak tasarlanan bağ kiriş modellerine ait donatı oranları ve alanları

\begin{tabular}{|c|c|c|c|c|c|c|}
\hline $\begin{array}{l}\text { Kesit } \\
\text { Grubu }\end{array}$ & $\begin{array}{c}\text { Kesit } \\
\text { No }\end{array}$ & $l_{n} / h$ & $\begin{array}{l}\text { Beton } \\
\text { Sinıfi }\end{array}$ & $\begin{array}{c}A_{s} \\
\left(m m^{2}\right)\end{array}$ & $\begin{array}{c}A_{s}^{\prime} \\
\left(m m^{2}\right)\end{array}$ & $\rho=\rho^{\prime}$ \\
\hline \multirow{5}{*}{ Tip-1 } & B1-1 & 2.0 & \multirow{15}{*}{30} & \multirow{5}{*}{$\begin{array}{l}4 \Phi 20 \\
1256.6\end{array}$} & \multirow{5}{*}{$\begin{array}{l}4 \Phi 20 \\
1256.6\end{array}$} & \multirow{5}{*}{0.005585} \\
\hline & B1-2 & 2.5 & & & & \\
\hline & B 1-3 & 3.0 & & & & \\
\hline & B 1-4 & 3.5 & & & & \\
\hline & B1-5 & 4.0 & & & & \\
\hline \multirow{5}{*}{ Tip-2 } & B2-1 & 2.0 & & \multirow{5}{*}{$\begin{array}{l}4 \Phi 26 \\
2123.7\end{array}$} & \multirow{5}{*}{$\begin{array}{l}4 \Phi 26 \\
2123.7\end{array}$} & \multirow{5}{*}{0.009439} \\
\hline & B2-2 & 2.5 & & & & \\
\hline & B2-3 & 3.0 & & & & \\
\hline & B2-4 & 3.5 & & & & \\
\hline & B2-5 & 4.0 & & & & \\
\hline \multirow{5}{*}{ Tip-3 } & B3-1 & 2.0 & & \multirow{5}{*}{$\begin{array}{l}4 \Phi 32 \\
3217\end{array}$} & \multirow{5}{*}{$\begin{array}{l}4 \Phi 32 \\
3217\end{array}$} & \multirow{5}{*}{0.01430} \\
\hline & B3-2 & 2.5 & & & & \\
\hline & B3-3 & 3.0 & & & & \\
\hline & B3-4 & 3.5 & & & & \\
\hline & B3-5 & 4.0 & & & & \\
\hline
\end{tabular}




\begin{tabular}{|c|c|c|c|c|c|c|}
\hline $\begin{array}{l}\text { Kesit } \\
\text { Grubu }\end{array}$ & Kesit No & $l_{n} / h$ & $\begin{array}{l}\text { Beton } \\
\text { Sinıfı }\end{array}$ & $\begin{array}{c}A_{s} \\
\left(m m^{2}\right)\end{array}$ & $\begin{array}{c}A_{s}^{\prime} \\
\left(m m^{2}\right)\end{array}$ & $\boldsymbol{\rho}=\boldsymbol{\rho}^{\prime}$ \\
\hline \multirow{5}{*}{ Tip-4 } & B4-1 & 2.0 & \multirow{15}{*}{45} & \multirow{5}{*}{$\begin{array}{l}4 \Phi 20 \\
1256.6\end{array}$} & \multirow{5}{*}{$\begin{array}{l}4 \Phi 20 \\
1256.6\end{array}$} & \multirow{5}{*}{0.005585} \\
\hline & B4-2 & 2.5 & & & & \\
\hline & B4-3 & 3.0 & & & & \\
\hline & B4-4 & 3.5 & & & & \\
\hline & B4-5 & 4.0 & & & & \\
\hline \multirow{5}{*}{ Tip-5 } & B5-1 & 2.0 & & \multirow{5}{*}{$\begin{array}{l}4 \Phi 26 \\
2123.7\end{array}$} & \multirow{5}{*}{$\begin{array}{l}4 \Phi 26 \\
2123.7\end{array}$} & \multirow{5}{*}{0.009439} \\
\hline & B5-2 & 2.5 & & & & \\
\hline & B5-3 & 3.0 & & & & \\
\hline & B5-4 & 3.5 & & & & \\
\hline & B5-5 & 4.0 & & & & \\
\hline \multirow{5}{*}{ Tip-6 } & B6-1 & 2.0 & & \multirow{5}{*}{$\begin{array}{l}4 \Phi 32 \\
3217\end{array}$} & \multirow{5}{*}{$\begin{array}{l}4 \Phi 32 \\
3217\end{array}$} & \multirow{5}{*}{0.01430} \\
\hline & B6-2 & 2.5 & & & & \\
\hline & B6-3 & 3.0 & & & & \\
\hline & B6-4 & 3.5 & & & & \\
\hline & B6-5 & 4.0 & & & & \\
\hline
\end{tabular}

\section{ARAŞTIRMA BULGULARI}

Detayları Tablo (3 ve 4)'te verilen ve tip 1, 2, 3, 4, 5 ve 6 olarak tasarlanan geleneksel donatılmış betonarme bağ kirişi modelleri için moment-eğrilik analizlerinden akma ve maksimum moment ve eğrilik değerleri hesaplanmıştır. Doğrusal olmayan davranışın iyi anlaşabilmesi için bağ kirişlerinin uçlarına yakın bölgelerde yığılı plastik mafsal oluştuğu varsayılmıştır. Yığılı plastik davranışına göre modellenen betonarme bağ kirişlerin $M_{y}, k_{y}, M_{u}, k_{u}, \mu$ ve $\theta_{y}$ değerleri hesaplanarak Tablo (5 ve 7)'de verilmiştir. Farklı tip betonarme bağ kirişlerinin değişen parametrelere göre hesaplanan $\left(\varepsilon_{\mathrm{c}}^{(\mathrm{SH})}\right),\left(\varepsilon_{\mathrm{s}}^{(\mathrm{SH})}\right),\left(\theta_{p}^{(\mathrm{SH})}\right),\left(\varepsilon_{c}^{(\mathrm{KH})}\right),\left(\varepsilon_{s}^{(\mathrm{KH})}\right),\left(\theta_{p}^{(K H)}\right),\left(\varepsilon_{c}^{(G \mathrm{O})}\right)$, $\left(\varepsilon_{s}^{(G O ̈)}\right)$ ve $\left(\theta_{p}^{(G \ddot{)})}\right)$ değerleri Tablo (6 ve 8$)$ 'de özetlenmiștir. Tablolarda $M_{y}, M_{u}$ değerleri; $k N \times m, K_{y}, K_{u}$ değerleri; $\operatorname{Rad} \times 1000 / m$ ve Etkin eğilme rijitliği değerleri; $k N \times m^{2}$ biriminde verilmiştir.

Geleneksel donatılmış betonarme bağ kirişi kesitlerinin analiz ve hesap sonuçlarından elde edilen değerler karşılaştırmalı olarak Şekil $(2,3,4,5$ ve 6)'da verilmiştir. Betonarme bağ kirişi modellerinde elde edilen GÖ ve KH performans düzeyi için izin verilen sargılı beton birim kısalması $\left(\varepsilon_{c}^{G O ̈ O}, \varepsilon_{c}^{K H}\right)$ değerlerinin net açıklık/derinlik oranına göre karşılaştırmalı grafikleri Şekil (2 ve 3)'te verilmiştir. GÖ ve KH performans düzeyi için izin verilen plastik dönme açılarının $\left(\theta_{P}^{G O ̈}, \theta_{P}^{K H}\right)$ net açıklık/derinlik oranına göre karşılaştırmalı grafikleri Şekil (4 ve 5)'te verilmiştir. Akma durumu dönme açısı $\left(\theta_{y}\right)$ net açıklık/derinlik oranına göre karşılaştırmalı grafikleri Şekil (6)'da verilmiştir.

TBDY (2018)'de donatı çeliği için göçme öncesi ve kontrollü hasar performans düzeylerinde verilen hasar sınırları $\left(\varepsilon_{s}^{(K H)}, \varepsilon_{s}^{(G)}\right)$, donatı çeliğinin çekme dayanımına karşı gelen birim uzama değerini sabit katsayılar ile çarparak elde edilmektedir $\left(\varepsilon_{s}^{(G \ddot{O})}=0.4 \varepsilon_{s u}, \varepsilon_{s}^{(K H)}=0.75 \varepsilon_{s}^{(G O ̈)}\right)$. Sınırlı hasar performans düzeyi için verilen hasar sınırı ise sabit bir değer olarak verilmektedir $\left(\varepsilon_{s}^{(S H)}=0.0075\right)$. Sınırlı hasar performans düzeyi için izin verilen beton birim kısalması TBDY 2018'e göre sabit değer olarak verilmektedir $\left(\varepsilon_{c}^{(S H)}=0.0025\right)$. Göçme öncesi ve kontrollü hasar performans düzeyi için verilen plastik dönme hasar sinırları $\theta_{P} ; k_{y}, k_{u}, L_{P}, L_{s}$ ve $d_{b}$ 'nin fonksiyonudur. Dolaysıyla basınç donatısı oranı, sargı donatısı oranı ve çekme donatısı oranı gibi $k_{y}$ ve $k_{u}$ değerlerini etkileyen parametreler $\theta_{P}$ 'yi de etkilemektedir. Sınırlı hasar performans düzeyinde taşıyıcı sistemlerde plastik mafsal oluşmasına izin verilmediği için farklı parametrelere göre betonarme kiriş kesitlerinde $\theta_{p}^{(S H)}=0$ elde edilmiştir. 


\begin{tabular}{|c|c|c|}
\hline & $\begin{array}{l}\text { BŞEÜ Fen Bilimleri Dergisi } \\
7(2), 574-587,2020\end{array}$ & $\begin{array}{r}\text { BSEU Journal of Science } \\
\text { DOI: } 10.35193 / \text { bseufbd.726859 }\end{array}$ \\
\hline & & 58-7575 (http://dergipark.gov.tr/bseufbd) \\
\hline
\end{tabular}

Tablo 5. Tip 1, 2 ve 3 olarak tasarlanan betonarme bağ kirişlerin $M_{y}, k_{y}, M_{u}, k_{u}, \mu$ ve $\theta_{y}$ değerleri

\begin{tabular}{|c|c|c|c|c|c|c|c|}
\hline \multirow{2}{*}{$\begin{array}{l}\text { Kesit } \\
\text { Grubu }\end{array}$} & \multirow{2}{*}{ Kesit No } & \multicolumn{2}{|c|}{ Akma Durumu } & \multicolumn{2}{|c|}{ Kırılma Durumu } & \multirow{2}{*}{$\boldsymbol{\mu}=\frac{\boldsymbol{k}_{\boldsymbol{u}}}{\boldsymbol{k}_{\boldsymbol{y}}}$} & \multirow{2}{*}{$\theta_{y}$} \\
\hline & & $M_{y}$ & $\boldsymbol{k}_{y}$ & $M_{u}$ & $\boldsymbol{k}_{\boldsymbol{u}}$ & & \\
\hline \multirow{5}{*}{ Tip-1 } & B1-1 & \multirow{5}{*}{398} & \multirow{5}{*}{0.0039} & \multirow{5}{*}{485} & \multirow{5}{*}{0.0359} & \multirow{5}{*}{9.2} & 0.00539 \\
\hline & B1-2 & & & & & & 0.00534 \\
\hline & B1-3 & & & & & & 0.00538 \\
\hline & B1-4 & & & & & & 0.00548 \\
\hline & B1-5 & & & & & & 0.00561 \\
\hline \multirow{5}{*}{ Tip-2 } & B2-1 & \multirow{5}{*}{638} & \multirow{5}{*}{0.0041} & \multirow{5}{*}{770} & \multirow{5}{*}{0.0355} & \multirow{5}{*}{8.6} & 0.00576 \\
\hline & B2-2 & & & & & & 0.00572 \\
\hline & B2-3 & & & & & & 0.00578 \\
\hline & B2-4 & & & & & & 0.00589 \\
\hline & B2-5 & & & & & & 0.00604 \\
\hline \multirow{5}{*}{ Tip-3 } & B3-1 & \multirow{5}{*}{937} & \multirow{5}{*}{0.0043} & \multirow{5}{*}{1126} & \multirow{5}{*}{0.0349} & \multirow{5}{*}{8.0} & 0.00615 \\
\hline & B3-2 & & & & & & 0.00613 \\
\hline & B3-3 & & & & & & 0.00620 \\
\hline & B3-4 & & & & & & 0.00633 \\
\hline & B3-5 & & & & & & 0.00649 \\
\hline
\end{tabular}

Tablo 6. Tip 1, 2 ve 3 olarak tasarlanan betonarme bağ kirişlerin hesaplanan performans seviyeleri

\begin{tabular}{|c|c|c|c|c|c|c|c|c|c|c|}
\hline \multirow{2}{*}{$\begin{array}{l}\text { Kesit } \\
\text { Grubu }\end{array}$} & \multirow{2}{*}{ Kesit No } & \multicolumn{2}{|l|}{ (SH) } & \multicolumn{3}{|c|}{ (KH) } & \multicolumn{3}{|c|}{ (GÖ) } & \multirow[b]{2}{*}{$\theta_{P}^{G \ddot{O}}$} \\
\hline & & $\varepsilon_{c}^{S H}$ & $\varepsilon_{s}^{S H}$ & $\theta_{P}^{S H}$ & $\varepsilon_{c}^{K H}$ & $\varepsilon_{s}^{K H}$ & $\theta_{P}^{K H}$ & $\varepsilon_{c}^{G \ddot{O}}$ & $\varepsilon_{s}^{G O ̈}$ & \\
\hline & B1-1 & & & & & & 0.00648 & & & 0.00864 \\
\hline & B1-2 & & & & & & 0.00667 & & & 0.00889 \\
\hline \multirow[t]{5}{*}{ Tip-1 } & B1-3 & 0.0025 & 0.0075 & 0 & 0.00979 & 0.024 & 0.00681 & 0.01306 & 0.032 & 0.00907 \\
\hline & B1-4 & & & & & & 0.00691 & & & 0.00921 \\
\hline & B1-5 & & & & & & 0.00699 & & & 0.00932 \\
\hline & B2-1 & & & & & & 0.00684 & & & 0.00913 \\
\hline & B2-2 & & & & & & 0.00703 & & & 0.00938 \\
\hline \multirow[t]{5}{*}{ Tip-2 } & B2-3 & 0.0025 & 0.0075 & 0 & 0.00986 & 0.024 & 0.00717 & 0.01314 & 0.032 & 0.00956 \\
\hline & B2-4 & & & & & & 0.00727 & & & 0.00969 \\
\hline & B2-5 & & & & & & 0.00734 & & & 0.00979 \\
\hline & B3-1 & & & & & & 0.00716 & & & 0.00954 \\
\hline & B3-2 & & & & & & 0.00734 & & & 0.00978 \\
\hline \multirow[t]{3}{*}{ Tip-3 } & B3-3 & 0.0025 & 0.0075 & 0 & 0.00991 & 0.024 & 0.00747 & 0.01322 & 0.032 & 0.00996 \\
\hline & B3-4 & & & & & & 0.00757 & & & 0.01009 \\
\hline & B3-5 & & & & & & 0.00764 & & & 0.01019 \\
\hline
\end{tabular}




\begin{tabular}{|c|c|c|}
\hline & $\begin{array}{l}\text { BŞEÜ Fen Bilimleri Dergisi } \\
7(2), 574-587,2020\end{array}$ & $\begin{array}{r}\text { BSEU Journal of Science } \\
\text { DOI: } 10.35193 / \text { bseufbd.726859 }\end{array}$ \\
\hline & & 58-7575 (http://dergipark.gov.tr/bseufbd) \\
\hline
\end{tabular}

Tablo 7. Tip 4, 5 ve 6 olarak tasarlanan betonarme bağ kirişlerin $M_{y}, k_{y}, M_{u}, k_{u}, \mu$ ve $\theta_{y}$ değerleri

\begin{tabular}{|c|c|c|c|c|c|c|c|}
\hline \multirow{2}{*}{$\begin{array}{l}\text { Kesit } \\
\text { Grubu }\end{array}$} & \multirow{2}{*}{ Kesit No } & \multicolumn{2}{|c|}{ Akma Durumu } & \multicolumn{2}{|c|}{ Kırılma Durumu } & \multirow{2}{*}{$\boldsymbol{\mu}=\frac{\boldsymbol{k}_{\boldsymbol{u}}}{\boldsymbol{k}_{\boldsymbol{y}}}$} & \multirow{2}{*}{$\theta_{y}$} \\
\hline & & $M_{y}$ & $\boldsymbol{k}_{y}$ & $M_{u}$ & $\boldsymbol{k}_{\boldsymbol{u}}$ & & \\
\hline \multirow{5}{*}{ Tip-4 } & B4-1 & \multirow{5}{*}{400} & \multirow{5}{*}{0.0038} & \multirow{5}{*}{485} & \multirow{5}{*}{0.0362} & \multirow{5}{*}{9.5} & 0.00520 \\
\hline & B4-2 & & & & & & 0.00514 \\
\hline & B4-3 & & & & & & 0.00518 \\
\hline & B4-4 & & & & & & 0.00527 \\
\hline & B4-5 & & & & & & 0.00540 \\
\hline \multirow{5}{*}{ Tip-5 } & B5-1 & \multirow{5}{*}{636} & \multirow{5}{*}{0.0040} & \multirow{5}{*}{771} & \multirow{5}{*}{0.0358} & \multirow{5}{*}{9.0} & 0.00548 \\
\hline & B5-2 & & & & & & 0.00544 \\
\hline & B5-3 & & & & & & 0.00548 \\
\hline & B5-4 & & & & & & 0.00559 \\
\hline & B5-5 & & & & & & 0.00572 \\
\hline \multirow{5}{*}{ Tip-6 } & B6-1 & \multirow{5}{*}{939} & \multirow{5}{*}{0.0042} & \multirow{5}{*}{1128} & \multirow{5}{*}{0.0353} & \multirow{5}{*}{8.5} & 0.00579 \\
\hline & B6-2 & & & & & & 0.00576 \\
\hline & B6-3 & & & & & & 0.00582 \\
\hline & B6-4 & & & & & & 0.00593 \\
\hline & B6-5 & & & & & & 0.00608 \\
\hline
\end{tabular}

Tablo 8. Tip 4, 5 ve 6 olarak tasarlanan betonarme bağ kirişlerin hesaplanan performans seviyeleri

\begin{tabular}{|c|c|c|c|c|c|c|c|c|c|c|}
\hline \multirow{2}{*}{$\begin{array}{l}\text { Kesit } \\
\text { Grubu }\end{array}$} & \multirow{2}{*}{$\begin{array}{c}\text { Kesit } \\
\text { No }\end{array}$} & \multicolumn{2}{|l|}{$(\mathbf{S H})$} & \multicolumn{3}{|c|}{ (KH) } & \multicolumn{3}{|c|}{ (GÖ) } & \multirow[b]{2}{*}{$\theta_{P}^{G \ddot{O}}$} \\
\hline & & $\varepsilon_{c}^{S H}$ & $\varepsilon_{s}^{S H}$ & $\theta_{P}^{S H}$ & $\varepsilon_{c}^{K H}$ & $\varepsilon_{s}^{K H}$ & $\theta_{P}^{K H}$ & $\varepsilon_{c}^{G \ddot{O}}$ & $\varepsilon_{s}^{G \ddot{O}}$ & \\
\hline & B4-1 & & & & & & 0.00655 & & & 0.00873 \\
\hline & B4-2 & & & & & & 0.00675 & & & 0.00899 \\
\hline \multirow[t]{5}{*}{ Tip-4 } & B4-3 & 0.0025 & 0.0075 & 0 & 0.00848 & 0.024 & 0.00688 & 0.01130 & 0.032 & 0.00918 \\
\hline & B4-4 & & & & & & 0.00699 & & & 0.00932 \\
\hline & B4-5 & & & & & & 0.00707 & & & 0.00942 \\
\hline & B5-1 & & & & & & 0.00693 & & & 0.00924 \\
\hline & B5-2 & & & & & & 0.00712 & & & 0.00949 \\
\hline \multirow[t]{5}{*}{ Tip-5 } & B5-3 & 0.0025 & 0.0075 & 0 & 0.00853 & 0.024 & 0.00726 & 0.01137 & 0.032 & 0.00967 \\
\hline & B5-4 & & & & & & 0.00736 & & & 0.00981 \\
\hline & B5-5 & & & & & & 0.00744 & & & 0.00991 \\
\hline & B6-1 & & & & & & 0.00727 & & & 0.00970 \\
\hline & B6-2 & & & & & & 0.00746 & & & 0.00994 \\
\hline \multirow[t]{3}{*}{ Tip-6 } & B6-3 & 0.0025 & 0.0075 & 0 & 0.00858 & 0.024 & 0.00759 & 0.01144 & 0.032 & 0.01012 \\
\hline & B6-4 & & & & & & 0.00769 & & & 0.01025 \\
\hline & B6-5 & & & & & & 0.00777 & & & 0.01036 \\
\hline
\end{tabular}




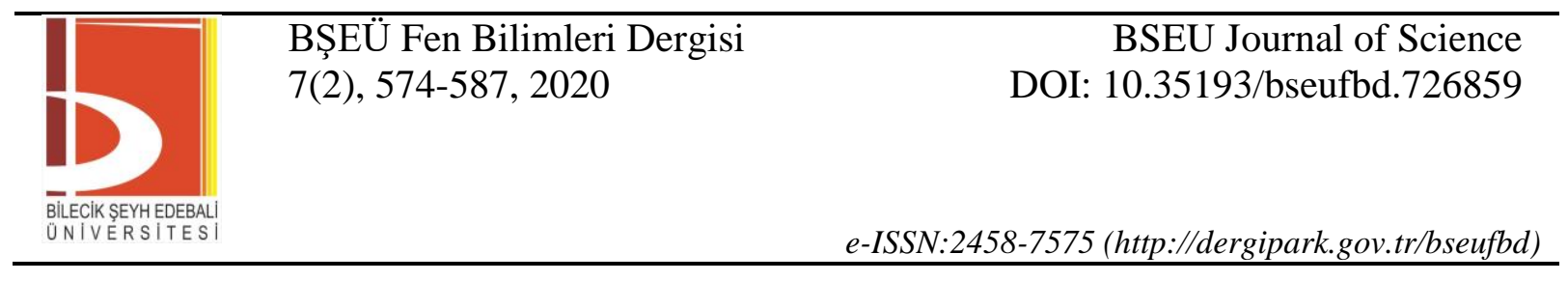

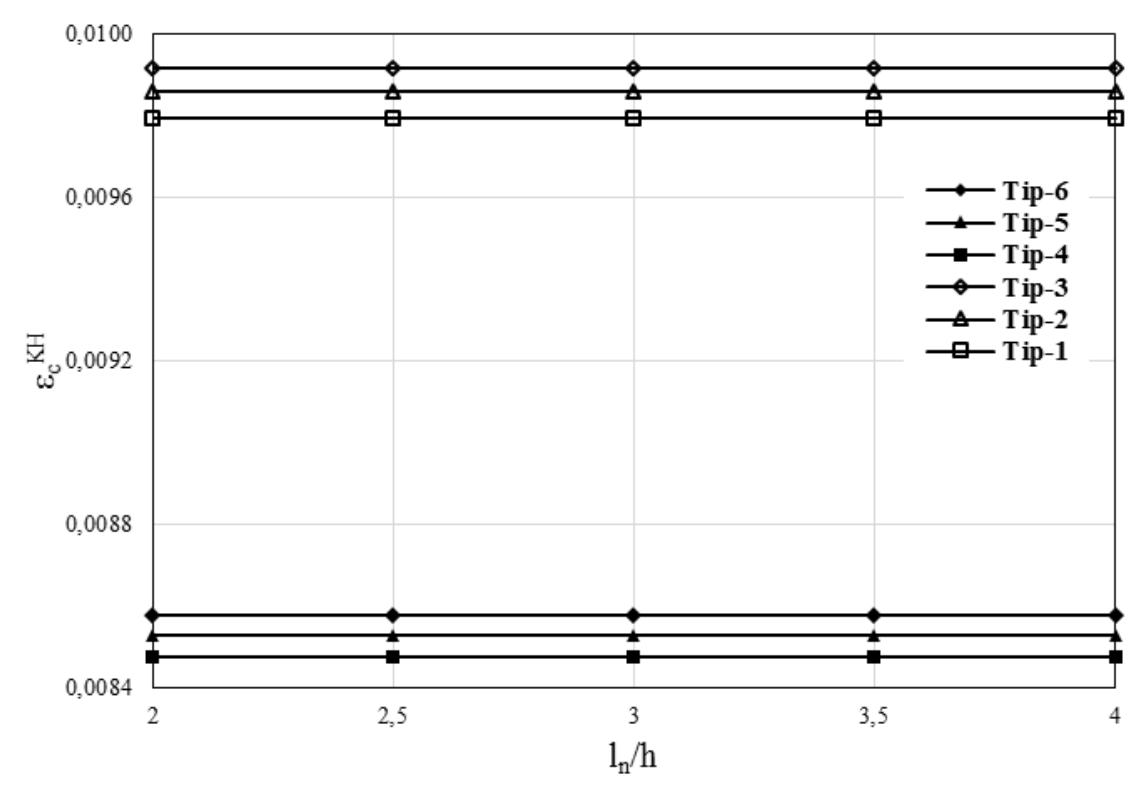

Şekil 2. Betonarme bağ kirişlerinin $\varepsilon_{\mathrm{c}}^{\mathrm{KH}}-\mathrm{l}_{\mathrm{n}} / \mathrm{h}$ değerlerinin karşılaştırılmalı grafikleri

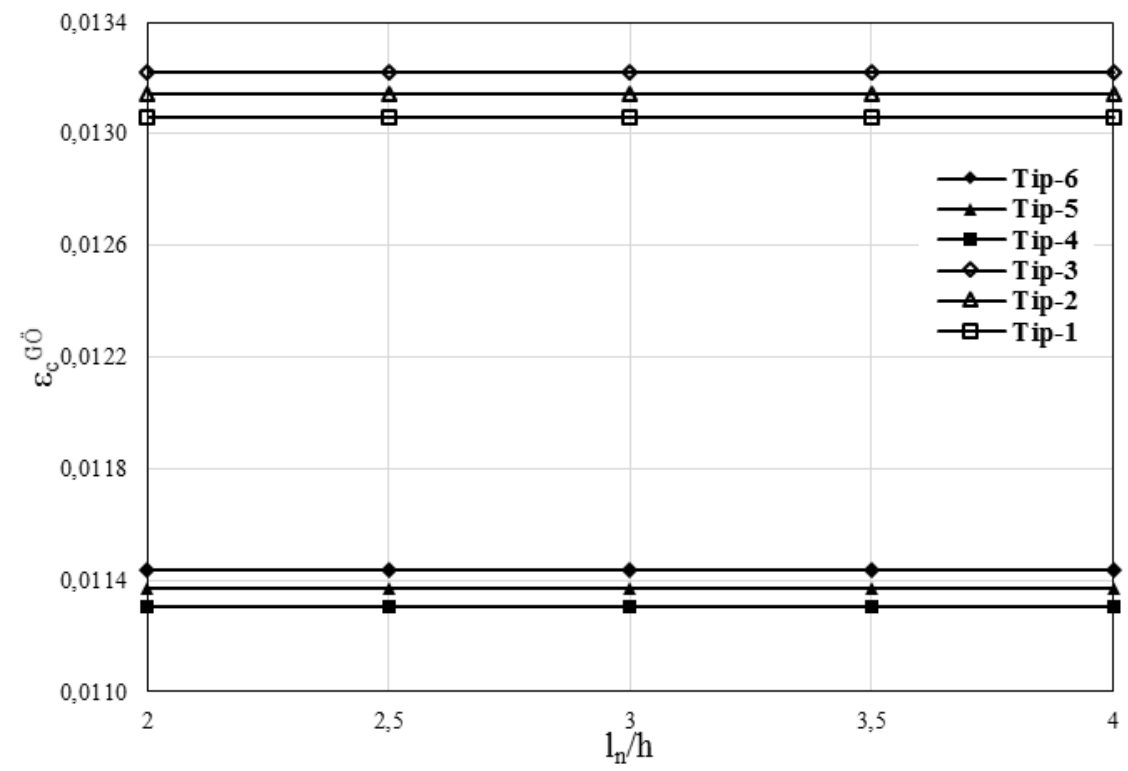

Şekil 3. Betonarme bağ kirişlerinin $\varepsilon_{c}^{\mathrm{GO}}-\mathrm{l}_{\mathrm{n}} / \mathrm{h}$ değerlerinin karşılaştırılmalı grafikleri 


\begin{tabular}{l|lr}
\hline \hline & $\begin{array}{l}\text { BŞEÜ Fen Bilimleri Dergisi } \\
7(2), 574-587,2020\end{array}$ & BSEU Journal of Science \\
& & \\
\hline $\begin{array}{c}\text { BiLECIKSEYHEDEBAL } \\
\text { UNIIERSITESI }\end{array}$ & & \\
\hline
\end{tabular}

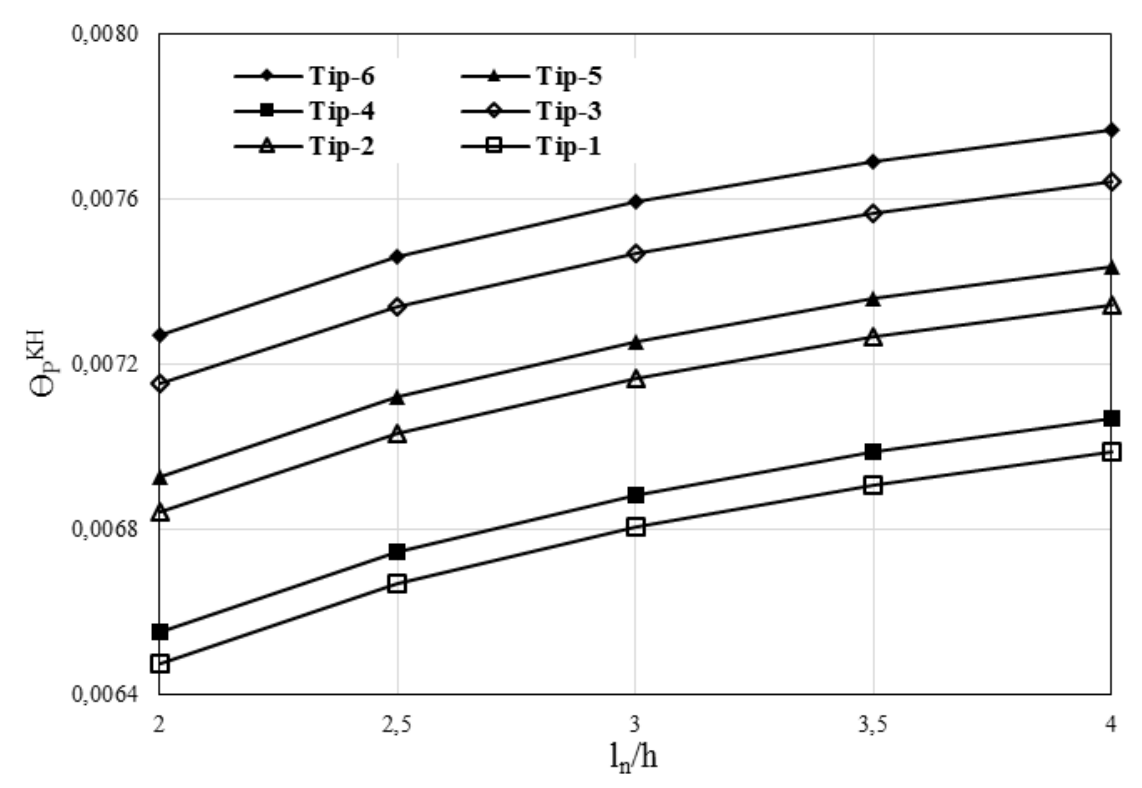

Şekil 4. Betonarme bağ kirişlerinin $\theta_{\mathrm{P}}^{\mathrm{KH}}-\mathrm{l}_{\mathrm{n}} / \mathrm{h}$ değerlerinin karşılaştırılmalı grafikleri

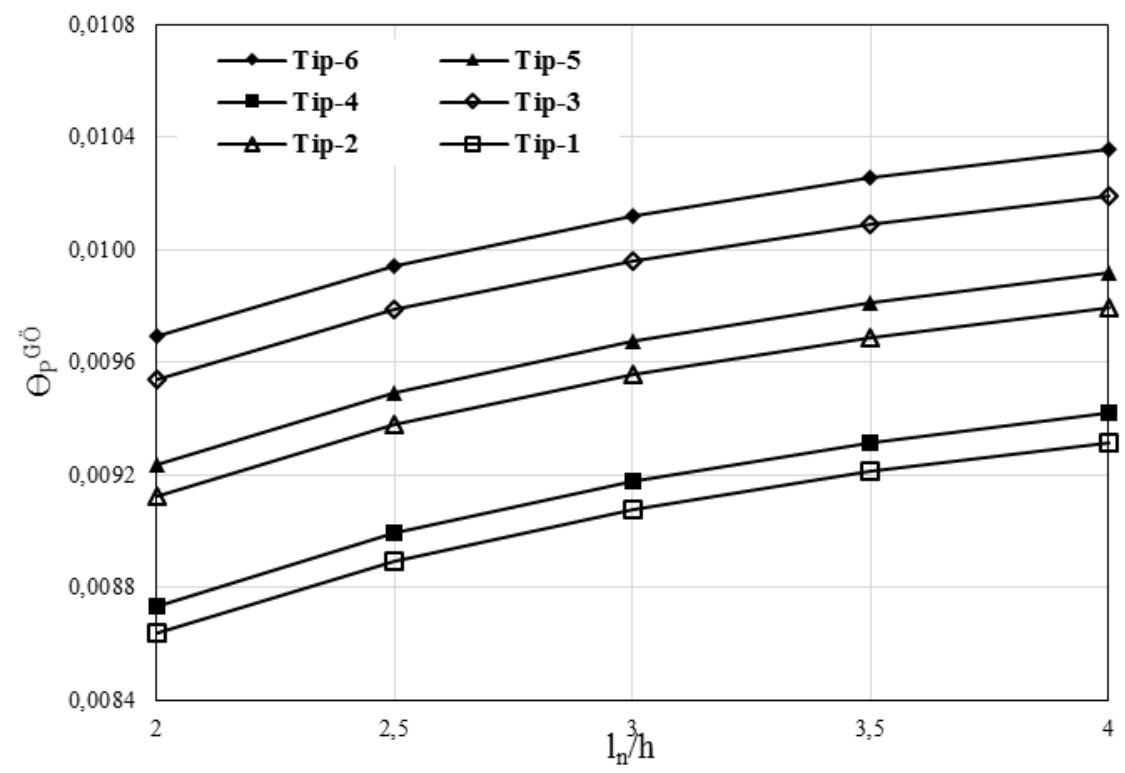

Şekil 5. Betonarme bağ kirişlerinin $\theta_{\mathrm{P}}^{\mathrm{GÖ}}-\mathrm{l}_{\mathrm{n}} / \mathrm{h}$ değerlerinin karşılaştırılmalı grafikleri 


\begin{tabular}{|c|c|c|}
\hline & $\begin{array}{l}\text { BŞEÜ Fen Bilimleri Dergisi } \\
7(2), 574-587,2020\end{array}$ & $\begin{array}{r}\text { BSEU Journal of Science } \\
\text { DOI: } 10.35193 / \text { bseufbd.726859 }\end{array}$ \\
\hline & & 88-7575 (http://dergipark.gov.tr/bseufbd) \\
\hline
\end{tabular}

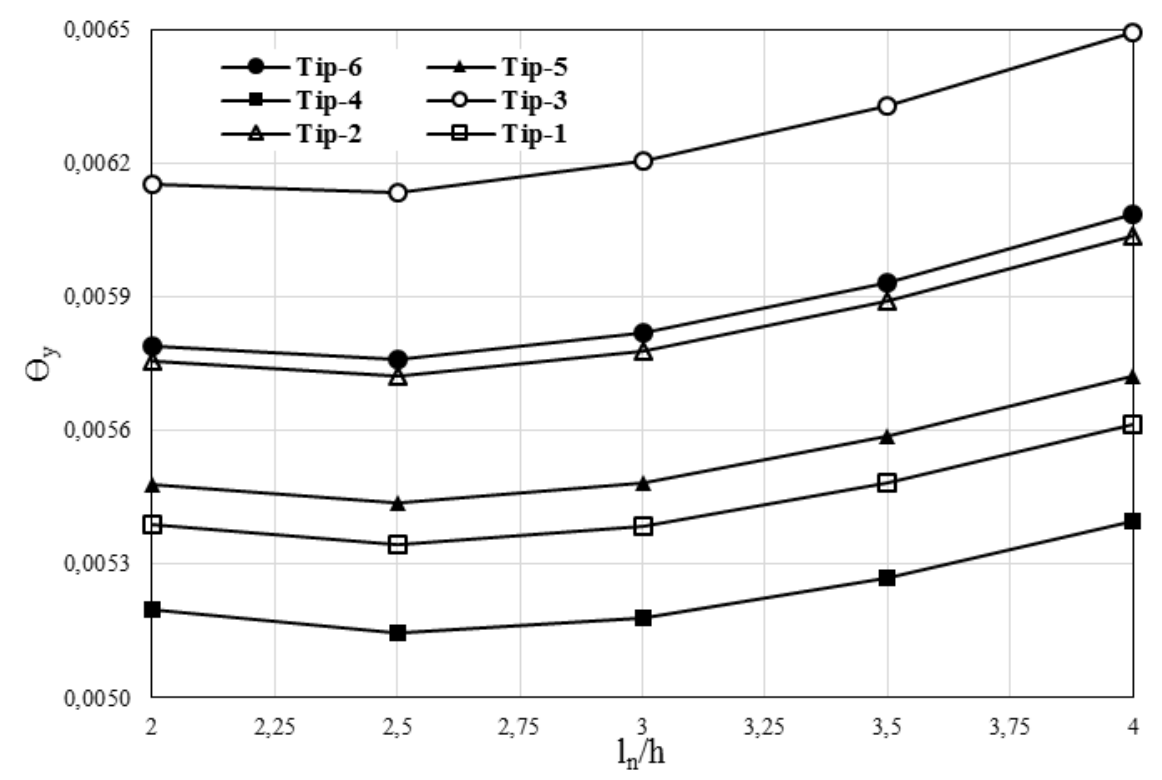

Şekil 6. Betonarme bağ kirişlerinin $\theta_{\mathrm{y}}-\mathrm{l}_{\mathrm{n}} / \mathrm{h}$ değerlerinin karşılaştırılmalı grafikleri

Geleneksel donatılmış betonarme bağ kirişlerin hasar sınırlarını tanımlayan birim şekil değiştirme ve iç kuvvet değerleri TBDY 2018'e göre hesaplanmıştır. Hesaplanan hasar sınırları diğer bir deyişle izin verilen beton birim kısalması, donatı çeliğin birim uzaması ve izin verilen dönme açıları Tablo (6 ve 8)'de verilmiştir. Araştırma bulgular bölümünde, betonarme bağ kirişlerinin davranışı için elde edilen yorum ve değerlendirmeler araştırma sonuçları bölümünde karşılaştırarak yorumlanmıştır.

\section{SONUÇ}

Araştırma bulgular bölümünde geleneksel donatılmış betonarme bağ kirişlerinin hasar sınırlarının sonuçları maddeler halinde aşağıda verilmiştir.

Geleneksel donatılmış betonarme bağ kirişlerinde; beton basınç dayanımının artması ile:

- Akma momenti $\left(M_{y}\right)$ ve maksimum moment $\left(M_{u}\right)$ değerleri yaklaşık olarak sabit kalmaktadır.

- Akma eğriliği $\left(k_{y}\right) \% 2,6$ azalmakta ve maksimum momente karşı gelen eğrilik $\left(k_{u}\right)$ değerleri $\% 0,83$ artmaktadır.

- Eğrilik süneklik $(\mu)$ değerleri yaklaşık \%3,26 artmaktadır.

- Plastik mafsal akma dönmesi $\left(\theta_{y}\right)$ değerleri \%3,5'den \%5,85'e kadar azalmaktadır.

- Kontrollü hasar ve Göçme öncesi performans düzeyinde izin verilen beton birim kısalması $\left(\varepsilon_{c}^{(K H)}\right.$ ve $\left.\varepsilon_{c}^{(G O ̈)}\right)$ değerleri \%13,4'ten \%13,48'e kadar azalmaktadır.

- Kontrollü hasar ve Göçme öncesi performans düzeyinde izin verilen plastik mafsal dönmesi değerleri $\left(\theta_{p}^{(K H)}\right.$ ve $\theta_{p}^{(G O ̈)}$ ) sirasıyla \%1,07'den \%1,84'e ve \%1,03’ten \%1,64'e kadar artmaktadır.

Geleneksel donatılmış betonarme bağ kirişlerinde; net açıklık derinlik oranının artması ile:

- Akma ve maksimum moment taşıma kapasitesi $\left(M_{y}, M_{u}\right)$, akma ve maksimum momente karş1 gelen eğrilikleri $\left(k_{y}, k_{u}\right)$ ve eğrilik süneklik $(\mu)$ değerleri sabit kalmaktadır.

- Net açıklık/derinlik oranı 2 ve 2.5 arasında olan betonarme bağ kirişlerde plastik mafsal akma dönme açısı değerleri $\left(\theta_{y}\right) \% 0,32$ 'den \%1,15'e kadar azalmaktadır. 
- Net açılılk derinlik oranı 2,5 ve 4 arasında olan betonarme bağ kirişlerde plastik mafsal akma dönme açısı değerleri $\left(\theta_{y}\right) \% 3,7^{\prime}$ den $\% 5,29$ 'e kadar artmaktadır.

- KH ve GÖ performans düzeyi için beton birim kısalması $\left(\varepsilon_{c}^{(K H)}\right.$ ve $\left.\varepsilon_{c}^{(G O ̈)}\right)$ değerleri sabit kalmaktadır.

- KH ve GÖ düzeyleri için izin verilen dönme açısı değerleri $\left(\theta_{p}^{(K H)}\right.$ ve $\left.\theta_{p}^{(G O ̈)}\right)$ sırasılyla $\% 6,28$ 'den $\% 11,7$ ve $\% 6,37$ 'den $\% 7,32$ 'ye kadar artmaktadır.

Geleneksel donatılmış betonarme bağ kirişlerinde; çekme ve basınç donatısı oranı artması ile:

- Akma momenti $\left(M_{y}\right) \% 135$, maksimum moment $\left(M_{u}\right) \% 132,2$ ve akma eğriliği $\left(k_{y}\right) \% 9,3$ 'ten \%10,5'e kadar değerleri artmaktadır.

- Maksimum momente karşı gelen eğrilik $\left(k_{u}\right) \% 2,55$ ’ten $\% 2,86$ ve eğrilik sünekliği $(\mu) \% 11,76$ 'dan $\% 15^{\prime}$ e kadar değerleri azalmaktadır.

- Plastik mafsal akma dönmesi $\left(\theta_{y}\right) \% 11,3$ ’ten \%15,7’ye kadar değerleri artmaktadır.

- Kontrollü hasar ve göçme öncesi performans düzeyinde izin verilen beton birim kısalması $\left(\varepsilon_{c}^{(K H)}\right.$ ve $\left.\varepsilon_{c}^{(G O ̈)}\right)$ sırasıyla $\% 1,2$ ve $\% 1,24$ değerleri artmaktadır.

- Kontrollü hasar ve göçme öncesi performans düzeyinde izin verilen dönme açıları $\left(\theta_{p}^{(K H)}\right.$ ve $\left.\theta_{p}^{(G O ̈)}\right)$ sirasıyla $\% 9,3$ 'ten $\% 10,99$ ve $\% 9,33$ 'ten $\% 11,11$ 'e kadar değerleri artmaktadır.

Beton basınç dayanımın artırılması, geleneksel donatılmış betonarme bağ kirişlerin akma momentine $\left(M_{y}\right)$, kırılma momentine $\left(M_{u}\right)$, kontrollü hasar ve göçmenin önlenmesi performans düzeyi dönme açılarına $\left(\theta_{p}^{(K H)}\right.$ ve $\left.\theta_{p}^{(G O ̈)}\right)$ etkili olduğu ispatlanmıştır.

Geleneksel donatılmış betonarme bağ kirişlerinin net açıklık derinlik/oranın artırılması; KH ve GÖ performans düzeyleri için izin verilen plastik dönme açılarına $\left(\theta_{P}^{(K H)}\right.$ ve $\theta_{P}^{(G O ̈)}$ ) ve akma durumu için yer değiştirmiş eksen dönmesi üzerine $\left(\theta_{y}\right)$ etkili olduğunu gözlemlenmiş̧tir.

Çekme ve basınç donatısı oranı artırılması, geleneksel donatılmış betonarme bağ kirişlerin akma ve maksimum moment taşıma kapasitesine, akma eğriliğine, akma dönme açısına, kontrollü hasar ve göçme öncesinin performans seviyesinde izin verilen beton birim kısalmasına ve dönme açılarına etkili olduğunu ispatlanmıştır.

\section{KAYNAKLAR}

[1] Ersoy, U. ve Özcebe G. (1998). Sarılmış Betonarme Kesitlerde Moment-Eğrilik İlişsisi Analitik Bir İnceleme. Teknik Dergi, 9(4), 1998-1827.

[2] Sönmez, İbrahim K, 2010. "Betonarme Yapı Sistemlerinde Yapısal Performans Düzeyini Belirleyen bir Bilgisayar Programı Geliştirilmesi”, Yüksek Lisans Tezi, İTÜ Fen Bilimleri Enstitüsü.

[3] S. F Breña, O. Ihtiyar, "Performance of conventionally reinforced coupling beams subjected to cyclic loading”. J StructEng, 137:665-76, 2011.

[4] S. El-Tawil, K. A. Harries, P. J. Fortney, B. M. Shahrooz, and Y. Kurama, "Seismic design of hybrid coupled wall systems: state of the art" Journal of structural engineering, vol. 136, no. 7, pp. 755-769, 2010.

[5] C.-C. Hung and W.-T. Lu, "A performance-based design method for coupled wall structures," Journal of Earthquake Engineering, vol. 21, no. 4, pp. 579-603, 2016.

[6] TBDY, 2018, Türkiye Bina Deprem Yönetmeliği, T.C. Bayındırlık ve İskân Bakanlığı, Ankara.

[7] SAP2000. Structural software for analysis and design, Computers and Structures, Inc. Version 20.0.0. USA. 


\begin{tabular}{|c|c|c|}
\hline & $\begin{array}{l}\text { BŞEÜ Fen Bilimleri Dergisi } \\
7(2), 574-587,2020\end{array}$ & $\begin{array}{l}\text { BSEU Journal of Science } \\
\text { DOI: } 10.35193 / \text { bseufbd } 726859\end{array}$ \\
\hline $\begin{array}{l}\text { BiLECIK SEYH EDEBALLI } \\
\text { UNIVERSITESI }\end{array}$ & & 58-7575 (http://dergipark.gov.tr/bseufbd) \\
\hline
\end{tabular}

[8] Çağlar, N., Akkaya, A., Demir, A., Öztürk, H., 2004. Farkll Kesit Geometrilerine Sahip Betonarme Kolonların Davranışının Incelenmesi, ISITES2014, p. 2095-2105, Karabük/Türkiye.

[9] TS500, 2000, Betonarme Yapıların Tasarım ve Yapım Kurallarl, Türk Standartları Enstitüsü, TSE, Ankara. 